\title{
Moldagem por Injeção de Pós Cerâmicos: Remoção da Parafina e do Polipropileno Utilizados como Veículo Orgânico
}

\author{
Ricardo V. B. Oliveira, Eduardo A. Pinheiro, Valdir Soldi, Alfredo T. N. Pires \\ Departamento de Química, UFSC
}

\author{
Márcio C. Fredel \\ Departamento de Engenharia Mecânica, UFSC
}

\begin{abstract}
Resumo: A moldagem por injeção de pós cerâmicos tem se tornado um processo altamente atrativo por aliar a versatilidade e a produtividade da moldagem por injeção convencional às propriedades inerentes aos materiais cerâmicos. A remoção do ligante, usado como veículo orgânico nesse processo, é uma das etapas críticas para a produção de peças cerâmicas sem defeitos. Neste trabalho avaliou-se a influência da geometria das peças injetadas na remoção do ligante, tanto por imersão em solvente como por decomposição térmica. Alumina em pó foi misturada fisicamente a um ligante composto por polipropileno [PP], parafina [PW] e ácido esteárico [AE]. As peças com diferentes geometrias foram mantidas imersas em hexano, secas sob vácuo e acompanhada a variação de massa devido à solubilização do $\mathrm{PW}$ e $\mathrm{AE}$. A determinação da porosidade das peças, realizada por meio das isotermas de adsorção/desorção de nitrogênio, mostrou um aumento de porosidade de $0,5 \%$ volume para aproximadamente $20 \%$ volume após a imersão em solvente. A remoção térmica do PP remanescente produziu hidrocarbonetos alifáticos e compostos insaturados, determinados e quantificados por espectroscopia de infravermelho, que permearam a estrutura porosa da peça. A geometria das peças tem grande influência na remoção do ligante, podendo afetar não só a qualidade do produto final, mas também as etapas subseqüentes do processo.
\end{abstract}

Palavras-chave: Moldagem por injeção, alumina, polipropileno, decomposição térmica.

\section{Ceramic Injection Molding: Removal of Pafafin and Polypropylene used as Organic Binder}

Abstract: Powder injection molding [PIM] has become highly attractive as it combines the versatility and productivity of conventional injection molding processes with the intrinsic properties of metallic and ceramic materials. The removal of organic binder, used as vehicles during the process, is one of the most critical stages in the production of ceramic devices in this process. In this work, the influence from the geometry of the injected part on the removal of the organic binder was evaluated for both solvent immersion and thermal degradation processes. Alumina powder was mixed with an organic binder, comprising polypropylene [PP], paraffin wax [PW] and stearic acid [SA], and injection molded in different geometries. Immersion of ceramic parts in hexane induced the solubilization of PW and SA, confirmed by weight variation. Parts porosity, determined through nitrogen adsorption isotherm, showed an increase from $0.5 \mathrm{v} \%$ before immersion to ca. $20 \mathrm{v} \%$ after immersion. PP burnout produced aliphatic hydrocarbons and unsaturated compounds that flow through a porous structure produced in early stages of this process. Parts geometry plays an important role in binder removal, affecting the quality of the sintered part as well as the remaining stages of the process.

Keywords: Powder injection molding, alumina, polypropylene, binder removal.

\section{Introdução}

A moldagem por injeção é um dos processos mais utilizados na transformação de material polimérico, devido principalmente à sua elevada produtividade e possibilidade de obtenção de peças com geometria complexa. Para a utilização de metais e materiais cerâmicos neste processo é necessária, além do próprio material particulado, a presença de componentes que possibilitem o processamento. A moldagem de pós por injeção [PIM] vem se tornando um processo de transformação altamente promissor, combinando a versatilidade e produtividade às propriedades dos materiais metálicos e cerâmicos. O mercado global da PIM movimentou 700 milhões de dólares em 2000, podendo chegar a 1 bilhão no final de $2003^{[1-3]}$. Um reflexo deste crescimento pode ser observado pelo aumento do número de publicações e de patentes relacionados com aplicações, como por exemplo, implantes ósseos, brackets ortodônticos, componentes de instrumentos musicais, armas de fogo e turbo-compressores para automóveis ${ }^{[4-13]}$.

Um esquema ilustrativo do processo de fabricação de uma peça cerâmica moldada por injeção é apresentado na Figura 1. As etapas consistem basicamente por: i) mistura física do pó cerâmico com o ligante, constituído essencialmente de

Autor para correspondência: Alfredo T. N. Pires, Departamento de Química, UFSC, Campus Universitário, Trindade, CEP: 88040-900, Florianópolis, SC. Email: pires@qmc.ufsc.br 


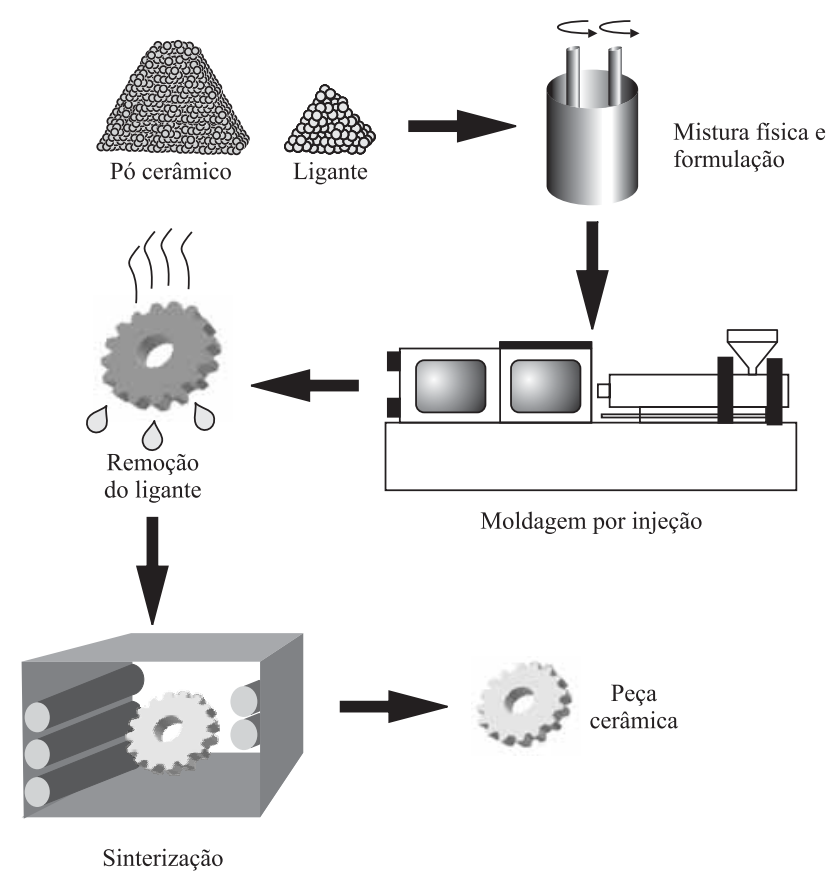

Figura 1. Esquema ilustrativo do processo de moldagem de pó cerâmico por injeção

material polimérico e aditivos; ii) injeção das peças, iii) remoção do ligante e; iv) processo de sinterização. Neste processo, uma das etapas críticas é a remoção do veículo orgânico, pois diferentes estratégias de remoção tais como remoção térmica e remoção do ligante por solvente vêm sendo utilizadas e desenvolvidas. Na remoção térmica o ligante é degradado em forno convencional ou em reator de plasma produzindo compostos voláteis com pequena massa molar. Por outro lado, na remoção do ligante por solvente é utilizado um processo físico que permite a recuperação do ligante e do solvente. Outras técnicas utilizadas envolvem a remoção do ligante por ação capilar ou por ação de vapor catalítico ${ }^{[10,14]}$.

Neste trabalho avaliou-se o processo de remoção do ligante em função da geometria da peça injetada, utilizando uma mistura de alumina com polipropileno, parafina e ácido esteárico como veículo orgânico.

\section{Experimental}

Neste trabalho foi utilizado pó de alumina (cod. A-1000) com diâmetro médio de $0,5 \mu \mathrm{m}$ e área superficial de $4,3 \mathrm{~m}^{2}$. $\mathrm{g}^{-1}$ fornecida pela Alcoa SA. Polipropileno [PP] (cod. H301), parafina $[\mathrm{PW}]$ com massa molar igual a $380 \mathrm{~g} \cdot \mathrm{mol}^{-1}$ (cód. 145P) e ácido esteárico $[\mathrm{AE}]$ foram fornecidos por Braskem S/A, Gewax e Sortex, respectivamente. Todos os componentes, sem purificação prévia, foram mantidos em estufa a vácuo por 12 $\mathrm{h}$ antes da utilização. As temperaturas de fusão e a composição da mistura são mostradas na Tabela 1 .

A mistura homogênea entre polipropileno, parafina e ácido esteárico foi obtida em um misturador do tipo sigma-blade (Haake/3000p Rheomix) a $180^{\circ} \mathrm{C}, 90 \mathrm{rpm}$. Alumina foi adicionada a esta mistura, ainda no misturador e mantida sob agitação durante $30 \mathrm{~min}$. Foram confeccionadas barras em uma
Tabela 1. Temperatura de fusão e composição da mistura.

\begin{tabular}{lccc}
\hline & & \multicolumn{2}{c}{$\begin{array}{c}\text { Composição da } \\
\text { mistura }\end{array}$} \\
\cline { 3 - 4 } Componente & $\begin{array}{r}\text { Temperatura } \\
\text { de Fusão }\left({ }^{\circ} \mathbf{C}\right)\end{array}$ & $\begin{array}{c}\% \text { em } \\
\text { massa }\end{array}$ & $\begin{array}{c}\% \text { em } \\
\text { volume }\end{array}$ \\
\hline Alumina[AL] & & 87 & 60 \\
Polipropileno [PP] & 170 & 6 & 19 \\
Parafina [PW] & 56 & 6 & 19 \\
Ácido Esteárico [AE] & 67 & 1 & 2 \\
\hline
\end{tabular}

Tabela 2. Parâmetros de injeção.

\begin{tabular}{lc} 
Velocidade de Injeção & $50 \mathrm{~mm} \mathrm{~s}^{-1}$ \\
Pressão de Injeção & $36 \mathrm{MPa}$ \\
Pressão de Recalque & $20 \mathrm{MPa}$ \\
Perfil de Temperatura & $140-150-160-170-175^{\circ} \mathrm{C}$ \\
Temperatura do Molde & $25^{\circ} \mathrm{C}$ \\
Tempo de Resfriamento & $30 \mathrm{~s}$ \\
\hline
\end{tabular}

Tabela 3. Dimensões das peças

\begin{tabular}{cccc}
\hline $\begin{array}{c}\text { Dimensões } \\
(\mathrm{mm})\end{array}$ & $\begin{array}{c}\text { Área } \\
\text { Superficial } \\
\left(\mathrm{mm}^{2}\right)\end{array}$ & $\begin{array}{c}\text { Volume } \\
\left(\mathrm{mm}^{3}\right)\end{array}$ & $\begin{array}{c}\mathrm{A}_{\mathrm{s}} / \mathrm{V} \\
\left(\mathrm{mm}^{-1}\right)\end{array}$ \\
\hline $1,8 \times 12,3 \times 18,0$ & 551,9 & 398,5 & 1,38 \\
$3,7 \times 5,5 \times 12,0$ & 261,5 & 244,2 & 1,07 \\
$3,7 \times 9,0 \times 25,0$ & 701,6 & 832,5 & 0,84 \\
\hline
\end{tabular}

injetora Arburg 3205/500, com os parâmetros de injeção indicados na Tabela 2. A partir destas barras, peças não sinterizadas (a verde) de 2,0 g com diferentes razões de área superficial/volume $\left[\mathrm{A}_{\mathrm{s}} / \mathrm{V}\right]$ foram cortadas com um disco de diamante (Isomet 650/ South Bay Technology Inc.), cujas dimensões estão especificadas na Tabela 3.

A unidade da razão $A_{s} / V$ será omitida por conveniência no decorrer deste trabalho.

As peças a verde foram submetidas à remoção da parte solúvel do ligante em hexano (Vetec - grau analítico) a 20,40 ou $60^{\circ} \mathrm{C}$, com acompanhamento da variação de massa em função do tempo. Para evitar saturação ou efeitos de gradiente de concentração, as peças foram imersas em hexano com fluxo contínuo $\left(2 \mathrm{~mL} \cdot \mathrm{min}^{-1}\right)$, de maneira que o solvente após destilado retornava ao sistema.

As isotermas de adsorção e de sorção de nitrogênio, a 77K, em peças injetadas, foram obtidas em um equipamento Quantachrome, modelo Autosorb - 1. O tamanho e a quantidade dos poros nas peças em função do tempo de imersão foram determinados a partir destas isotermas, utilizando o tratamento matemático proposto por Barret, Joyner e Halenda ${ }^{[15]}$, denotado por método BJH. Este método assume: i) adsorção 


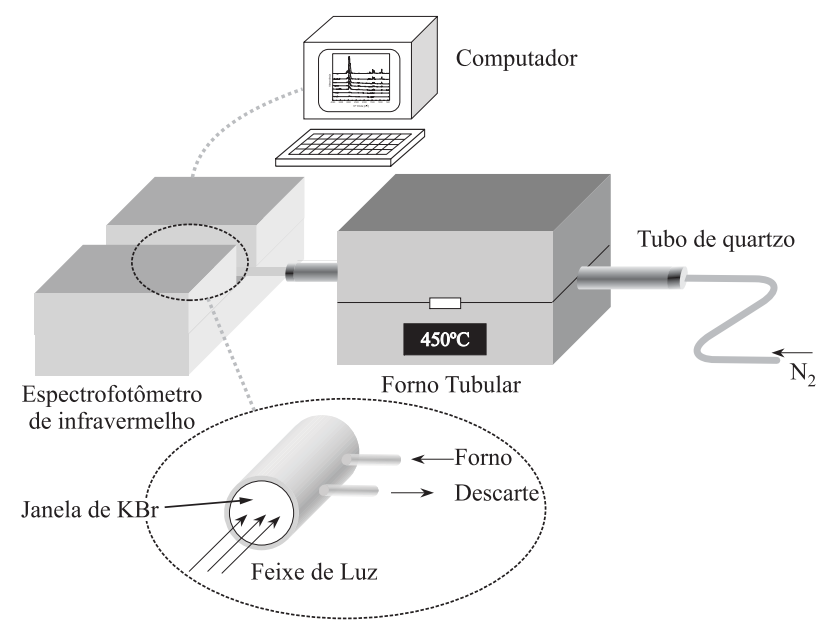

Figura 2. Esquema ilustrativo da montagem do sistema de análise de produtos gasosos formados durante decomposição térmica ${ }^{[16]}$

física do nitrogênio na parede interna dos poros e ii) posterior condensação capilar, onde o preenchimento pelo nitrogênio condensado depende do tamanho do poro e da pressão relativa $\left[\mathrm{P} / \mathrm{P}_{0}\right]$.

Amostras (ca. $20 \mathrm{mg}$ ) foram submetidas à análise termogravimétrica em atmosfera de nitrogênio $\left(50 \mathrm{~mL}\right.$. $\left.\mathrm{min}^{-1}\right)$ e taxa de aquecimento de $10^{\circ} \mathrm{C} . \mathrm{min}^{-1}$, em um equipamento Shimadzu TGA-50. Micrografias das superfícies de fratura das peças foram obtidas em um microscópio eletrônico de varredura Phillips XL-30.

Após a remoção por solvente da $\mathrm{PW}$ e $\mathrm{AE}$, as peças foram submetidas à remoção isotérmica do $\mathrm{PP} \mathrm{a} 450^{\circ} \mathrm{C}$, em um forno tubular sob atmosfera de nitrogênio $\left(50 \mathrm{~mL} \cdot \mathrm{min}^{-1}\right)$, acoplado a um espectrofotômetro de infravermelho (PerkinElmer 16-PC ${ }^{[16]}$. O esquema ilustrativo do sistema é mostrado na Figura 2, permitindo acompanhar a liberação de gases provenientes da decomposição térmica do PP na peça.

\section{Resultados e Discussão}

A razão da massa de ligante solúvel removida pela massa de ligante solúvel adicionada à mistura $[\phi]$ em função do tempo de imersão em hexano, para diferentes geometrias (quantificadas pela razão $\mathrm{A}_{\mathrm{s}} / \mathrm{V}$ ) e temperaturas, é mostrada na Figura 3. A remoção da $\mathrm{PW}$ e $\mathrm{AE}$ nas peças com maior área de contato com o solvente por unidade de volume (maior valor de $\mathrm{As} / \mathrm{V}$ ), conforme esperado, ocorreu em menor tempo (Figura 3a). Entretanto, independentemente da geometria, os componentes solúveis foram removidos completamente, sem produzir defeitos aparentes nas peças. Por outro lado para uma mesma geometria, a cinética de remoção do ligante é diretamente proporcional à temperatura. Para peças com $\mathrm{A}_{\mathrm{s}} / \mathrm{V}$ igual a 1,07, após 1 hora de imersão em hexano, ocorreu uma solubilização com um valor de $\phi$ da ordem de 0,8 a $60{ }^{\circ} \mathrm{C}$. (Figura 3b). Para a temperatura de $20{ }^{\circ} \mathrm{C}$ apenas $15 \%$ do ligante solúvel foi removido, sendo observado comportamento análogo para as demais geometrias estudadas. A influência da temperatura sobre a cinética de remoção está relacionada
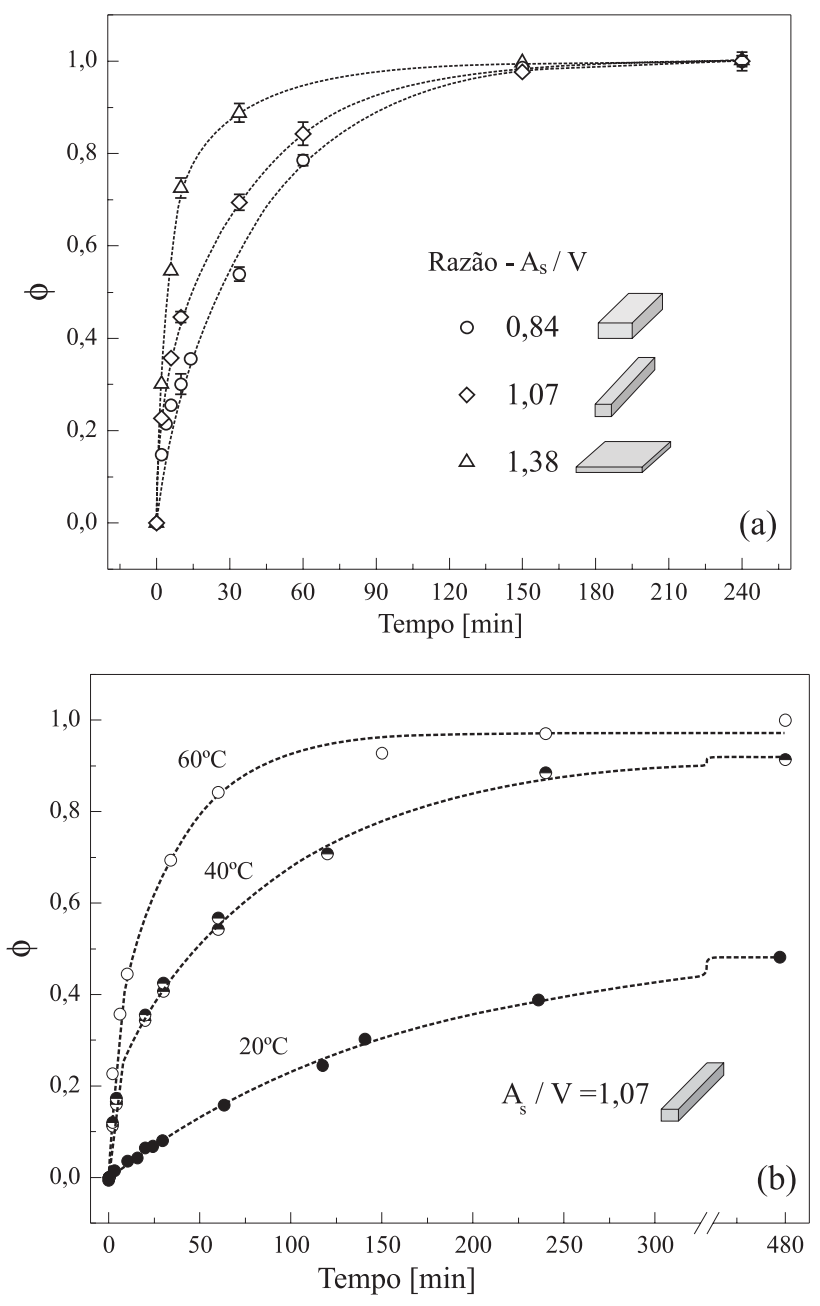

Figura 3. A razão da massa de ligante solúvel removida pela massa de ligante solúvel adicionada à mistura $(\phi)$ em função do tempo de imersão em hexano para (a) diferentes geometrias e (b) diferentes temperaturas.

com mudanças no parâmetro de solubilidade dos componentes e/ou mudanças na difusividade dos componentes em solução. A análise espectroscópica do resíduo de evaporação do solvente utilizado para remoção do veículo orgânico mostrou apenas bandas de absorção características do PW e AE,

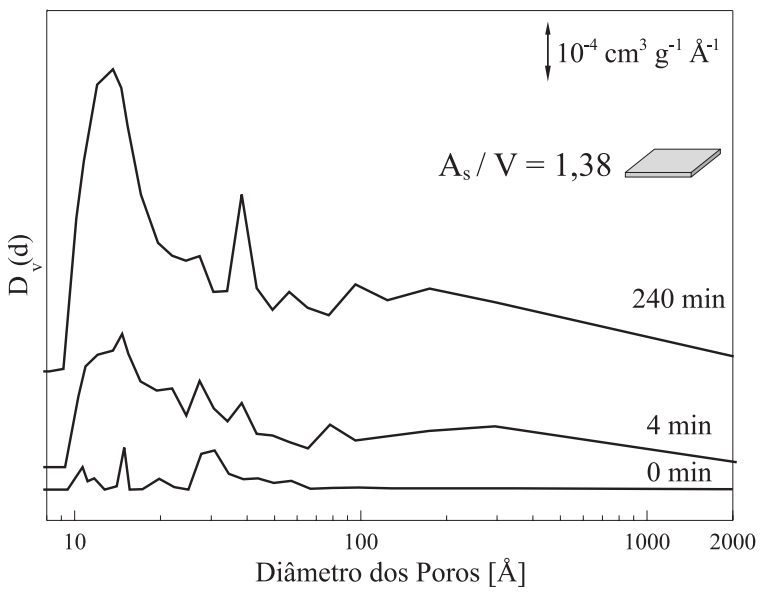

Figura 4. Curvas de distribuição de tamanhos de poros em função do tempo de imersão em hexano a $60{ }^{\circ} \mathrm{C}$ 


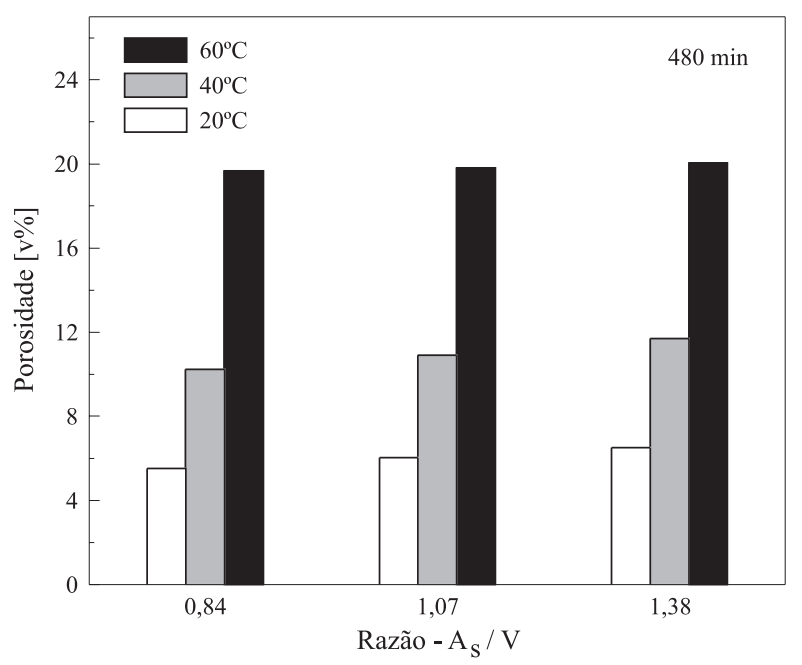

Figura 5. Porosidade volumétrica das peças com diferentes geometrias após imersão em solvente durante $480 \mathrm{~min}$.

indicando que a alumina e polipropileno, conforme esperado, não foram solubilizados nesta etapa do processo.

As curvas de distribuição de tamanho de poros nas peças em função do tempo de imersão no solvente foram obtidas por meio de isotermas de adsorção/desorção de nitrogênio, mostrando que a quantidade de poros é diretamente proporcional ao tempo de imersão, tanto na região de microporos $(10-50 \AA)$ como nas regiões de meso $(50-500 \AA)$ e macroporos $(>500 \AA)$. Peças a verde com $\mathrm{A}_{\mathrm{s}} / \mathrm{V}$ igual a 1,38 apresentaram pequena quantidade de poros menores do que
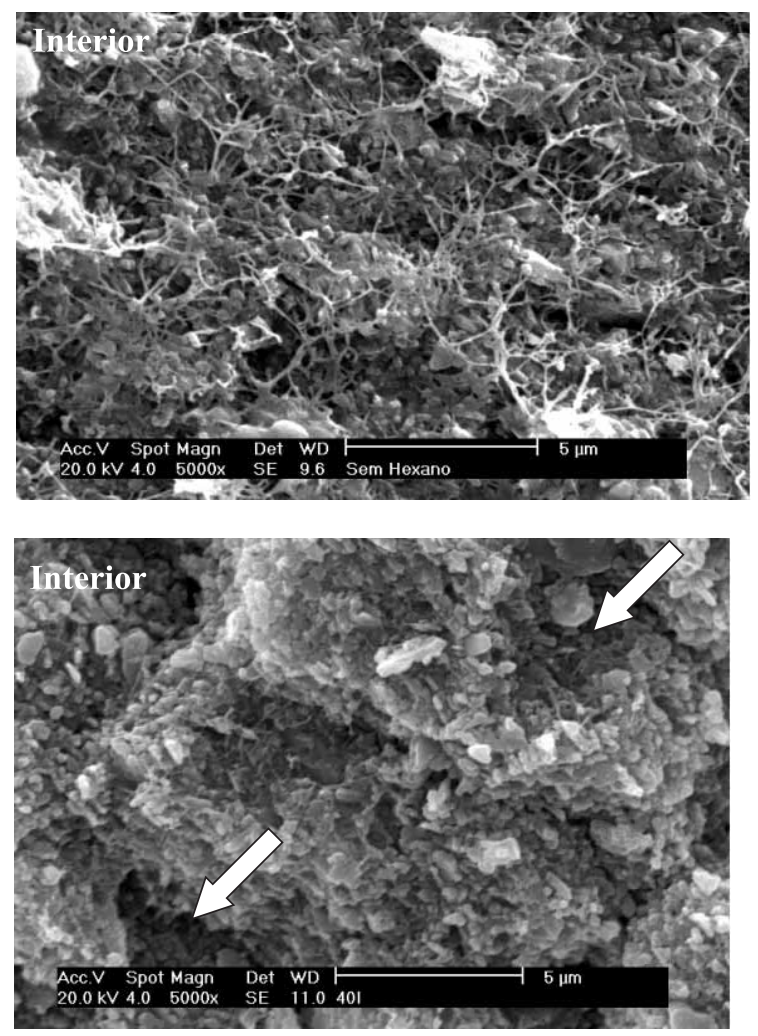

(a)

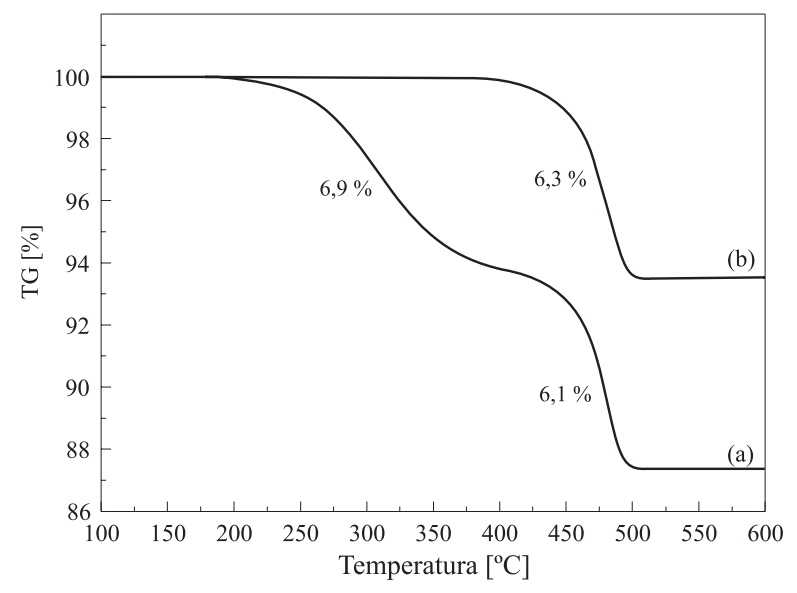

Figura 6. Curva de análise termogravimétrica: (a) da peça a verde e (b) após 480 min de imersão em hexano a $60^{\circ} \mathrm{C}$.

70 Å, conforme ilustrado na Figura 4. Após 4 min de imersão predominaram os microporos, sendo que após $4 \mathrm{~h}$, além da quantidade elevada de microporos observou-se o aparecimento de poros maiores do que $100 \AA$ que correspondem a maior volume vazio em relação ao volume total da peça. As percentagens de vazios (porosidade) no interior das peças foram calculadas através das áreas das curvas de distribuição de poros e das densidades aparentes. A Figura 5 apresenta a percentagem de porosidade das peças após $480 \mathrm{~min}$ de imersão no solvente a diferentes temperaturas. As peças mantidas a $60{ }^{\circ} \mathrm{C}$ atingiram a porosidade de $20 \%$, correspondente ao volume ocupado pela $\mathrm{PW}$ e AE na peça a ver-

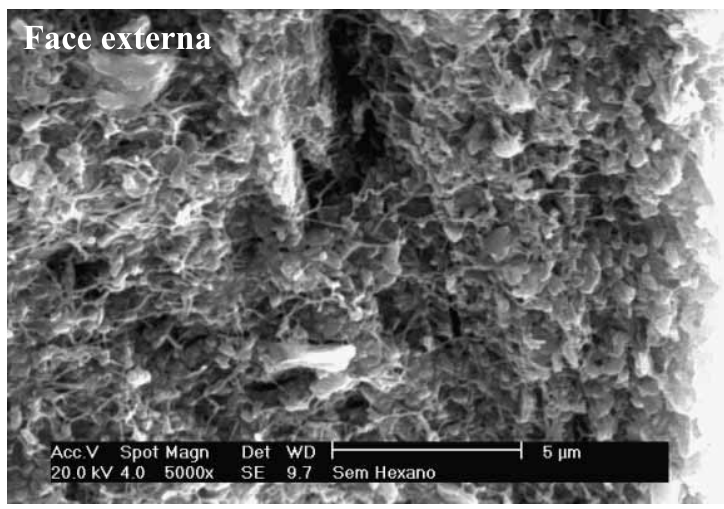

(b)

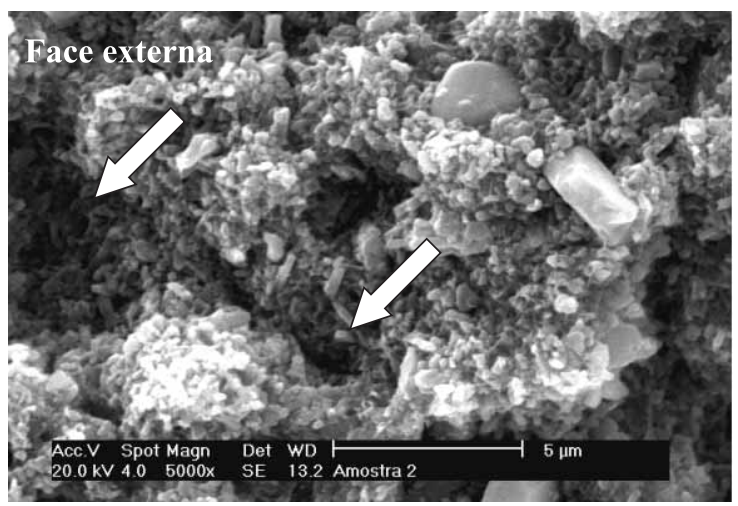

Figura 7. Micrografias de MEV de superfície fraturada de: (a) peça a verde e (b) peça mantida em hexano a $60{ }^{\circ} \mathrm{C}$ durante 480 min. As setas mostram regiões de vazios devido à remoção da parte solúvel do ligante 
de, sugerindo que praticamente todo o componente solúvel foi removido. Comportamento análogo foi observado para outras geometrias.

Para uma avaliação do grau dos componentes solúveis, peças antes e após tratamento com solvente foram analisadas por termogravimetria [TG]. A Figura 6a mostra a curva de Tg para a amostra da peça a verde com porcentagem de perda de massa concordante com as quatidades dos componentes da mistura injetada. A primeira região de perda de massa de $6,9 \%$ corresponde ao processo de decomposição de $\mathrm{PW}$ e $\mathrm{AE}$ e a segunda região de perda de massa de $6,1 \%$ corresponde à decomposição do $\mathrm{PP}$, nas faixas de temperatura de $210 \mathrm{a}$ $375^{\circ} \mathrm{C}$ e 380 a $490{ }^{\circ} \mathrm{C}$, respectivamente. A curva de TG da amostra de peças após imersão em solvente por 480 min mostra apenas o segundo processo de degradação com perda de massa de $6,3 \%$ devido à presença remanescente do PP. Esse valor concorda com a percentagem final do PP na peça, preparada a partir da mistura com proporção inicial de $\mathrm{Al}$ e $\mathrm{PP}$ de 87:6, considerando que a parafina e o ácido esteárico foram solubilizados no hexano.

A Figura 7 mostra as micrografias de MEV de superfícies de fratura das peças a verde e após remoção da parte solúvel do ligante, de regiões do interior e próximo à face externa. Conforme esperado, a morfologia da peça a verde apresentou as mesmas características ao longo de toda a superfície de fratura (Figura 7a). Nas micrografias da superfície de fratura da peça que foi mantida em hexano a $60{ }^{\circ} \mathrm{C}$ durante 480 min (Figura 7b), observam-se regiões de vazios indicadas pelas setas e exposição das partículas de alumina, devido à remoção da parte solúvel do ligante, em toda a extensão da superfície fraturada. Essa característica de apresentar textura homogênea ao longo de toda a peça é um importante fator nas etapas posteriores do processo, tais como remoção térmica do polipropileno e sinterização, bem como evitar falhas devido à existência de gradientes de densidade na peça sinterizada. Essa estrutura porosa permite a permeação dos produtos gasosos formados durante a degradação térmica do polímero, do interior à face externa e evitando acúmulo inter-

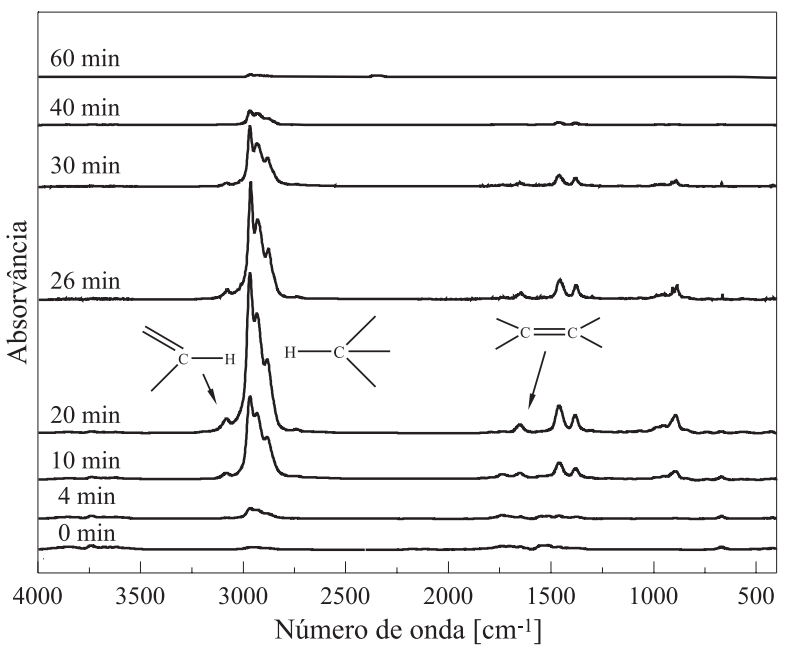

Figura 8. Espectros de infravermelho dos produtos gasosos formados durante a remoção térmica do $\mathrm{PP}$ a $450{ }^{\circ} \mathrm{C}$.

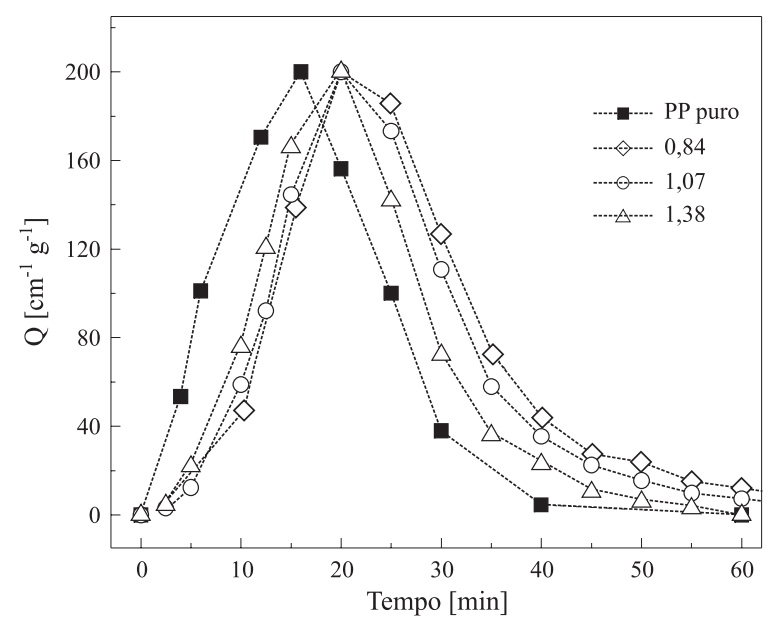

Figura 9. Quantidade de produtos gasosos $[Q]$ formados durante a decomposição térmica do $\mathrm{PP}$ a $450{ }^{\circ} \mathrm{C}$ em função do tempo.

no de gases com conseqüente não conformidade do produto final.

A Figura 8 mostra os espectros de infravermelho dos produtos gasosos formados, na degradação térmica do PP remanescente na peça com $\mathrm{A}_{\mathrm{s}} / \mathrm{V}$ de 1,07 , em função do tempo de permanência em um forno tubular à temperatura de $450^{\circ} \mathrm{C}$, conforme descrito na parte experimental. As bandas de absorção características de estiramentos $-\mathrm{C}-\mathrm{H},=\mathrm{C}-\mathrm{H}$ e $-\mathrm{C}=\mathrm{C}$ - observadas em 2985, 2850, 3050 e $1608 \mathrm{~cm}^{-1}$ respectivamente indicam a formação de hidrocarbonetos alifáticos e compostos insaturados durante a decomposição ${ }^{[17-19]}$. Considerando que os espectros de infravermelho dos gases liberados foram adquiridos em fluxo constante de nitrogênio (Figura 2), a redução da intensidade das bandas indica que uma menor quantidade de produtos gasosos está sendo produzida. Para as diferentes geometrias das peças estudadas, tempo da ordem de $60 \mathrm{~min}$ foram suficientes para a completa remoção térmica do PP. Os espectros de infravermelho dos produtos gasosos formados da decomposição térmica do PP puro apresentam as mesmas bandas de absorção quando este se encontra na peça, sugerindo o mesmo mecanismo de decomposição e possível inexistência de interações com a alumina.

A velocidade de remoção do PP em uma estrutura cerâmica porosa foi avaliada através da quantidade de gases produzidos, determinados a partir da área sob a curva nos espectros de infravermelho, na faixa de 3200 a $2750 \mathrm{~cm}^{-1}$, normalizadas para a mesma massa inicial de PP. Esta área denotada por $Q$, com unidades de $\mathrm{cm}^{-1} \mathrm{~g}^{-1}$, foi acompanhada em função do tempo, conforme mostrado na Figura 9. Tanto para o PP puro, como no interior das peças, as curvas da quantidade $Q$ em função do tempo apresentaram o mesmo perfil. É importante salientar que a diferença no tempo de remoção do PP puro quando comparado ao PP nas peças com diferentes geometrias, deve-se ao efeito da difusão dos gases, bem como a presença de poros interconectados na peça. A interconectividade entre os poros permite a eliminação dos compostos formados na decomposição, sugerindo que a etapa anterior de remoção por solvente foi efetiva, concordando com os resultados de isotermas de adsorção/desorção de nitrogênio e análise de microscopia eletrônica. 


\section{Conclusões}

A geometria da peça é um fator importante na remoção do veículo orgânico, tanto na etapa de remoção por solvente como na etapa de decomposição térmica. Para peças com maior valor da razão da área pelo volume, a remoção do ligante solúvel é facilitada devido à maior área de contato entre a peça e o solvente por unidade de volume. A formação de poros interconectados permite a eliminação dos gases formados na peça durante a decomposição térmica do PP, sem aparente mudança do mecanismo de degradação. A estabilidade dimensional da peça não foi comprometida, sendo que em uma etapa posterior de estudo, o processo de sinterização e a avaliação das características e propriedades mecânicas das peças cerâmicas produzidas deverão ser criteriosamente correlacionadas.

\section{Referências Bibliográficas}

1. German, R. M. \& Cornwall, R. G. - Int. J. Powder Metall., 37, p. 40-44 (2001).

2. Piotter, V.; Merz, L.; Ruprecht, R. \& Hausselt, J. - “Current status of micro powder injection molding”, in: Anais do Thermec'2003, Pts 1-5, p. 4233-4238, ZurichUetikon, (2003).

3. Willians, B. - Metal Powder Report, 57, p. 6-7 (2002).

4. Wu, Y.; Si, W. J.; Jing, Y. S.; Miao, H. Z. \& Yu, E. P. Rare Metal Mat. Eng., 32, p. 54-57 (2003).

5. Lombardo, S. J. \& Feng, Z. C. - J. Mater. Res., 17, p. 14341440 (2002).

6. Zhu, B. J.; Qu, X. H.; Tao, Y.; Xiao, P. G. \& Qin, M. L. Rare Metal Mat. Eng., 31, p. 303-307 (2002).

7. Merz, L.; Rath, S.; Piotter, V.; Ruprecht, R.; RitzhauptKleissl, J. \& Hausselt, J. - Microsyst. Technol., 8, p. 129-132 (2002).
8. Hu, M.; Zhou, D.; Zhang, D.; Lu, W.; Li, B.; Huang, J. \& Gong, S. - Mater. Sci. Eng. B, 99, p. 403-407 (2003).

9. Belhadjhamida, H. - United State Patent Application Publication, US 2002/0058136 A1, Mold-Masters Limited (2002).

10. Bishop, I. H. \& Masheder, D. - United States Patent, 6,197,252 B1, AVX Limited, Paignton (GB) (2001).

11. Tang, X. - United States Patent, 5,599,890, Rhom and Haas Company, Philadelphia, Pa. (1997).

12. Chatterjee, D. K.; Ghosh, S. K. \& Hutchinson, W. J. United State Patent, 6,156,246, Eastman Kodak Company (2000).

13. Meinhardt, H.; Meyer, B.; Knuwer, M.; Fister, D. \& Wiezoreck, W. - United State Patent Application Publication, US 2002/0068005 A1, Bayer Corporation (2002).

14. German, R. M. \& Bose, A. - "Injection molding of metals and ceramics", 1 ed., Metal Powder Industry Federation, Princeton (1997).

15. Barret, E. P.; Joyner, L. G. \& Halenda, P. P. - Journal of the American Chemical Society, 73, p. 373-380 (1951).

16. Severgnini, V. L. S. - "Estudo da degradação térmica do poli(cloreto de vinila-co-acetato de vinila-co-2 hidroxipropil acrilato) e seus homopolímeros", Dissertação de Mestrado, Universidade Federal de Santa Catarina, (2002).

17. Lattimer, R. P. - J. Anal. Appl. Pyrolysis, 26, p. 65-92 (1993).

18. Chan, J. H. \& Balke, S. T. - Polym. Degrad. Stabil., 57, p. 135-149 (1997).

19. Gao, Z. M.; Kaneko, T.; Amasaki, I. \& Nakada, M. Polym. Degrad. Stabil., 80, p. 269-274 (2003).

Enviado: $23 / 10 / 03$

Reenviado: $23 / 03 / 04$

Aprovado: 18/05/04 